\title{
Enhanced estimation of glacier mass balance in unsampled areas by means of topographic data
}

\author{
Luca CARTURAN, ${ }^{1}$ Federico CAZORZI, ${ }^{2}$ Giancarlo DALLA FONTANA ${ }^{1}$ \\ ${ }^{1}$ Department of Land and Agro-forest Environments, University of Padova, Viale dell'Università 16, 35020 Legnaro (PD), Italy \\ E-mail: luca.carturan@unipd.it \\ ${ }^{2}$ Department of Agriculture and Environmental Sciences, University of Udine, Via delle Scienze 208, 33100 Udine, Italy
}

\begin{abstract}
A new method was developed to estimate the mass balance in unsampled areas from existing datasets. Three years of mass-balance data from two glaciers in the central Italian Alps were used to develop and test a multiple-regression method based exclusively on a $10 \mathrm{~m}$ resolution digital terrain model. The introduction of a relative elevation attribute, which expresses the degree of wind exposure of the gridcells, notably increased the amount of explainable variance in winter balance with respect to altitude itself. The summer balance is highly correlated with elevation, but, in order to obtain reliable extrapolations, the clear-sky shortwave radiation and the diurnal cloud-cover cycle had to be taken into account. The net annual mass balance on a glacier system comprising the two monitored glaciers was calculated by applying both a single regression of winter and summer balance with altitude and the new regression method. The consistency of results was assessed against measured net balances and snowcover maps drawn in the ablation season. The results of the new method were in close agreement with observations and proved to be less sensitive to the spatial representation of the sampled areas.
\end{abstract}

\section{INTRODUCTION}

The remarkable mass losses that currently affect glaciers in the European Alps may lead to significant future alterations in the hydrology of glaciated catchments. The glacial stream flow regime shows a typical maximum in mid- to late summer, meeting the human requirements for water supply. In addition, glaciers have a damping effect with respect to climatic variations, storing mass during cold and wet periods and releasing it in warm, dry years. This mitigating capability sharply decreases as climatic forcing continues, leading to a strong reduction in glacier area and volume.

Knowledge of the spatial and temporal distribution of glacier mass balance is crucial both for climatic sensitivity studies and for understanding the hydrological behaviour of headwater basins (Fountain and others, 1999). For hydrologic investigation purposes, particularly, the glaciers that feed the main stream of a catchment should be regarded as a single system, characterized by complex behaviour and a strongly differentiated response to climatic changes.

Direct mass-balance measurements are only feasible on a few suitable glaciers (Østrem and Brugman, 1991; Kaser and others, 2003). Extensive surveys are not practical because measurement zones should meet certain requirements such as appropriate size, altitudinal range, geometry, accessibility and safety. Such constraints often lead to data being only partially representative of the whole glaciated area. The spatial interpolation and extrapolation of point massbalance data are prone to errors, in particular when data are few and sparse. In this case, computer plotting results are often poor when compared with hand-drawn mass-balance maps (Kaser and others, 2003); however, manual massbalance interpolations and extrapolations involve some subjectivity. The mass-balance gradient with altitude can be reliably estimated even with a small network of stakes, provided they are scattered over the elevation range of the glaciated area (Fountain and Vecchia, 1999). However, special care should be taken both in the case of strong lateral mass-balance gradients (Holmlund and Jansson, 1999) and when extrapolating field data to nearby glaciers with different sizes, geometries, feeding sources, debris cover and surrounding topography. Krimmel (1999) attributed the discrepancy between mass-balance estimates by direct and geodetic methods on South Cascade Glacier, Washington, USA, to possible uncertainties in the area-integration procedure, and to sinking stakes.

The mass-balance spatial distribution pattern is quite similar from year to year, since it is mainly controlled by the local topography, which affects both accumulation and ablation processes. Therefore, it is interesting to verify the feasibility of using topographically based attributes to assess the spatial variability of these dominant processes, by means of regression analyses.

The aim of this work is to develop and test a simple method to extrapolate direct mass-balance measurements in unsampled areas of benchmark glaciers or in nearby unsurveyed glaciers. After a description of the study area and field campaigns, we explain how the extrapolation scheme was implemented and applied to the glacial system of a headwater basin of the central Italian Alps. Thereafter, we focus on the results and critically discuss the applicability of the technique, its limits and possible improvements.

\section{STUDY AREA DESCRIPTION AND DATA COLLECTION}

The area we investigated is the upper sector of the Val de La Mare (UVLA), Trentino, Italy (see Fig. 1). Its physical and geographic characteristics make it representative of alpine, high-altitude catchments. The basin has an area of $36.2 \mathrm{~km}^{2}$ and an average altitude of $2906 \mathrm{~m}$, ranging from 1931 to $3769 \mathrm{~m}$, at the Cevedale peak. The catchment lies in the southern sector of the Ortles-Cevedale massif, the most glaciated area in the Italian Alps. At present, $25 \%$ of its surface is covered by four glaciers $\left(9.2 \mathrm{~km}^{2}\right)$ and the annual runoff regime is dominated by snow- and ice melt. In spite of its high average altitude, the area is easily accessible and 


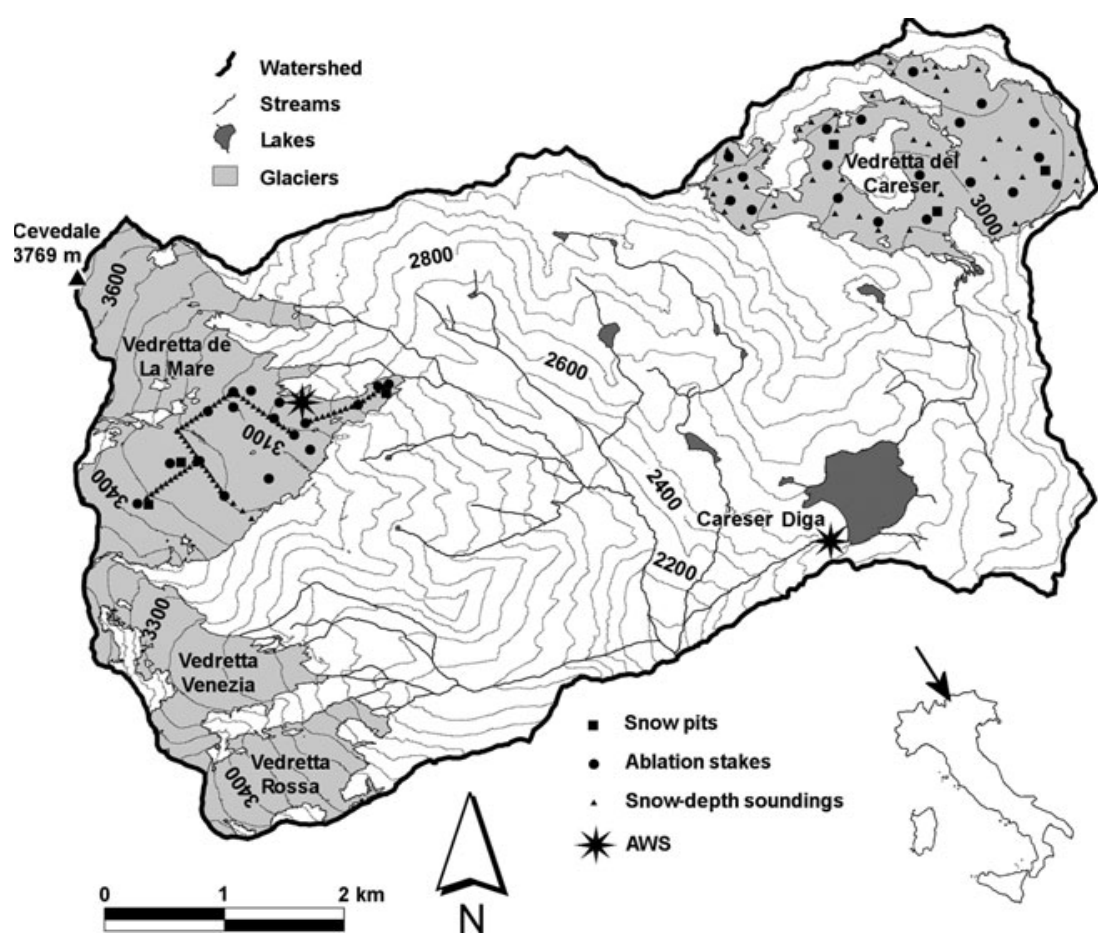

Fig. 1. Geographical setting of the study area.

comprises the glacier with the longest mass-balance data series in Italy (Careser). Moreover, for the Careser Diga station $(2605 \mathrm{~m})$ the weather data series extends back to 1930 .

The Val de La Mare is located near the inner dry Alpine zone (Schwarb, 2000). Therefore precipitation is less abundant than in the nearby Adamello-Presanella and Brenta massifs and the average equilibrium-line altitude (ELA) is higher. At Careser Diga, the mean annual precipitation is $927 \mathrm{~mm}$ and the October-May precipitation averages $556 \mathrm{~mm}$. The mean annual air temperature is $-0.7^{\circ} \mathrm{C}$, while from June to September it averages $6.0^{\circ} \mathrm{C}$. The altitude of the mean annual zero isotherm is $2500 \mathrm{~m}$.

Direct mass-balance measurements have been performed since 1967 on Careser glacier, and extend until the present without interruption (Carturan and Seppi, 2007). As can be seen in Table 1, the Careser glacier geometry is peculiar when compared to the entire glacial system, $95 \%$ of its surface being concentrated between 2858 and $3200 \mathrm{~m}$. A long series of strongly negative mass balances has led to rapid surface lowering and fragmentation as the entire glacier lies below the recent years' average ELA ( 3400 m). In addition, albedo and elevation feedbacks emphasize the climate forcing.
The other three glaciers (Vedretta Rossa, Venezia and La Mare) are located on the western slope of the basin and are characterized by higher mean altitudes. Their geometry suggests a possible minor mass change in response to the recent rise of ELA and a lower response time than Careser glacier (Furbish and Andrews, 1984; Benn and Evans, 1998; Pelto and Hedlund, 2001). This is confirmed by the terminus behaviour in the last several decades, characterized by continuous retreat of Careser and temporary but substantial readvance of the other three glaciers from 1970 to 1985 . The presence of crevassed areas and the observed displacement of boulders on the surfaces are evidence of flow on these three glaciers, while repeated global positioning system (GPS) surveys of ablation stakes on Careser glacier denote a complete absence of movement. The different activity of the four glaciers is also evident from the accumulation-area ratio (AAR) values from 2004 to 2006 (Table 2). Vedretta Rossa, Venezia and La Mare appear less in disequilibrium with the present climatic conditions.

In order to set up an adequate experimental basis for our research activity, a series of field surveys was undertaken in the past 5 years. In the summer of 2003, we started direct

Table 1. Physical characteristics of UVLA glaciers. The elevations are in metres above sea level. ELA65 and ELA50 are the equilibrium-line altitudes corresponding to accumulation-area ratios of 0.65 and 0.50 , respectively

\begin{tabular}{|c|c|c|c|c|c|c|c|c|}
\hline Glacier & $\begin{array}{l}\text { Area } \\
\mathrm{km}^{2}\end{array}$ & $\begin{array}{c}\text { Minimum elevation } \\
\mathrm{m}\end{array}$ & $\begin{array}{c}\text { Maximum elevation } \\
\mathrm{m}\end{array}$ & $\begin{array}{c}\text { Average elevation } \\
\mathrm{m}\end{array}$ & $\begin{array}{c}\text { Average slope } \\
\%\end{array}$ & $\begin{array}{c}\text { Prevalent aspect } \\
\circ\end{array}$ & $\begin{array}{l}\text { ELA65 } \\
\mathrm{m}\end{array}$ & $\begin{array}{l}\text { ELA50 } \\
\qquad \mathrm{m}\end{array}$ \\
\hline Careser & 2.83 & 2858 & 3296 & 3052 & 21 & 177 & 3028 & 3063 \\
\hline La Mare & 4.01 & 2640 & 3769 & 3277 & 39 & 92 & 3198 & 3270 \\
\hline Venezia & 1.37 & 2851 & 3703 & 3256 & 48 & 108 & 3154 & 3217 \\
\hline Rossa & 0.99 & 2712 & 3645 & 3222 & 55 & 58 & 3147 & 3223 \\
\hline $\begin{array}{l}\text { UVLA glacier } \\
\text { system }\end{array}$ & 9.19 & 2640 & 3769 & 3199 & 37 & 117 & 3105 & 3166 \\
\hline
\end{tabular}



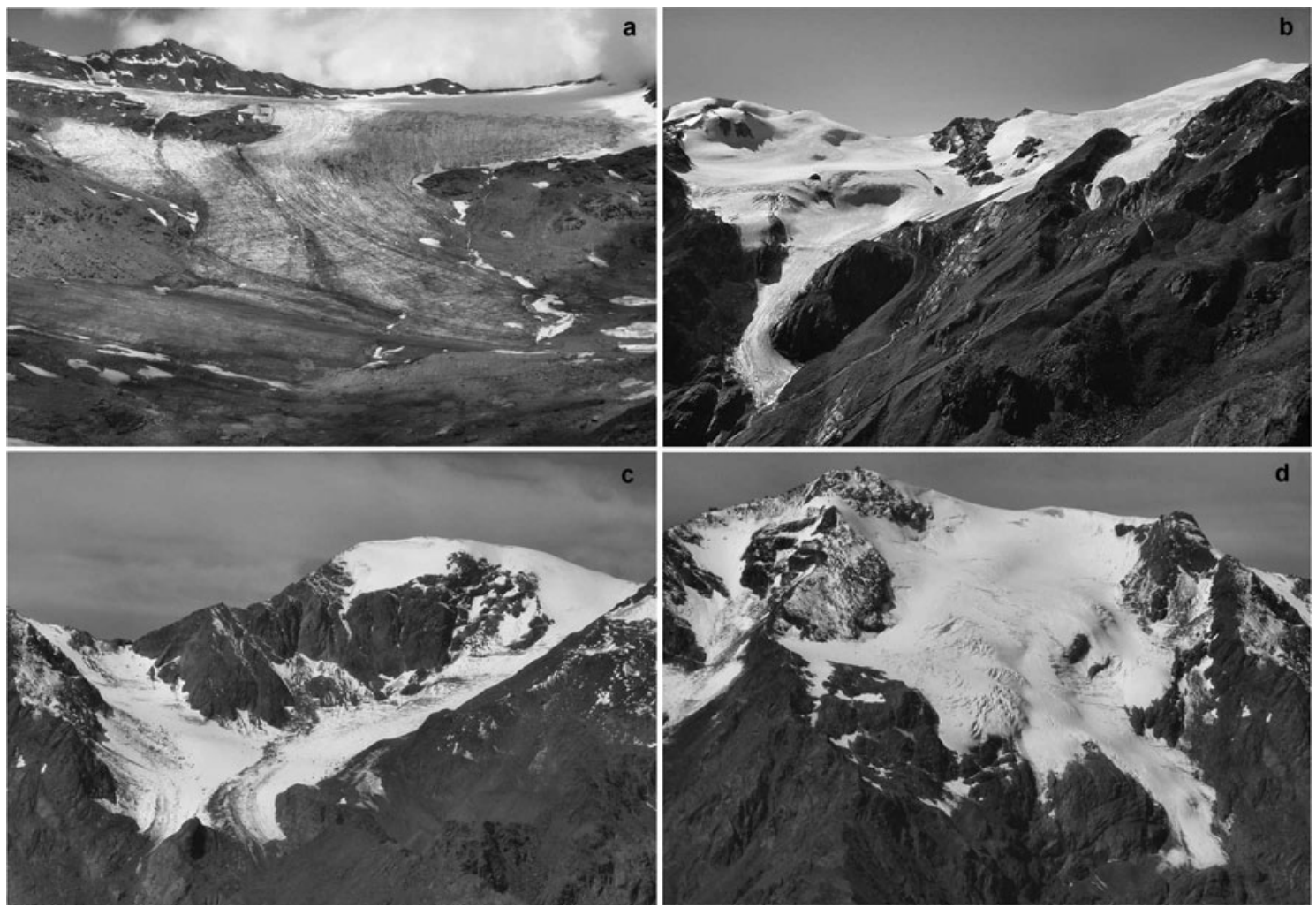

Fig. 2. The four glaciers of the UVLA catchment. (a) Vedretta del Careser, (b) Vedretta de La Mare, (c) Vedretta Venezia and (d) Vedretta Rossa. Photographs taken by L. Carturan in 2007.

mass-balance observations over the more representative Vedretta de La Mare, with the aim of completing our knowledge about the mass-balance behaviour of the entire glacier system. Winter and summer balance measurements have been carried out since 2004 in order to understand the climatic causes of mass changes. An automatic weather station (AWS) has been operated from the summer of 2005 on the surface of the glacier, and in 2007 portable albedo measurements were conducted on Careser and La Mare glaciers. Repeated mapping of snow cover on the four glaciers was performed using terrestrial photographs at 2 week intervals during summer.

Vedretta de La Mare can be considered a 'difficult' glacier since it presents highly crevassed areas, seracs and steep slopes, and it is not possible to survey the whole surface in one day. Therefore, we focused on the southern sector, which feeds the main tongue (Figs 1 and 2).

Winter balance $\left(b_{\mathrm{w}}\right)$ measurements were carried out on both glaciers in the last 10 days of May, combining snowdepth soundings with density measurements in snow pits for the calculation of point snow water equivalent (w.e.). On Careser glacier, the entire area was investigated. On La Mare glacier the soundings were limited to safe areas, and in 2004 and 2005 specific points were selected in accordance with the snow-cover patterns observed in previous summers. In 2006, the soundings were performed at regular distances along rectilinear transects. The $b_{\mathrm{w}}$ data were little affected by ablation, which was limited to the lowest area of La Mare glacier.

Summer balance $\left(b_{\mathrm{s}}\right)$ measurements were conducted in the last 10 days of September with $2 \mathrm{~m}$ aluminium stakes, drilled into the ice or firn with a hand auger; the stakes located in firn were plugged at the lower end with insulating material, in order to avoid sinking. In the accumulation area, snow-depth soundings were taken and snow pits were dug both for density measurements and for the identification of previous-year layers. The net accumulation was measured on the maximum accumulation areas, where residual snow persisted even in the extremely warm 2003 summer.

Both glaciers are currently experiencing strong mass losses, which are mainly controlled by $b_{\mathrm{s}}$ and only occasionally heightened by low $b_{\mathrm{w}}$ (Zanon, 1982; Carturan and Seppi, 2007).

For the years 2004, 2005 and 2006, an average number of $125 b_{\mathrm{w}}$ and $32 b_{\mathrm{s}}$ measurements for Careser and La Mare glaciers was usable for the implementation and validation of the extrapolation scheme. As reported in Table 2, the accumulation season precipitation was slightly below average in 2004 and 2005 and well below average in 2006. Ablation seasons were warmer and longer than normal. In 2004 the peak of ablation was reached in late

Table 2. Accumulation-area ratios for the UVLA glaciers in the years 2004-06 and corresponding anomalies in accumulation season precipitation and ablation season temperature from the 1967 to 2006 averages, at the Careser Diga weather station

\begin{tabular}{lccc}
\hline & 2004 & 2005 & 2006 \\
\hline Careser & 0.02 & 0.01 & 0.00 \\
La Mare & 0.24 & 0.21 & 0.16 \\
Venezia & 0.22 & 0.12 & 0.09 \\
Rossa & 0.18 & 0.15 & 0.14 \\
Oct.-May precipitation anomaly & $-5 \%$ & $-10 \%$ & $-29 \%$ \\
Jun.-Sep. temperature anomaly & $+1.1^{\circ} \mathrm{C}$ & $+1.0^{\circ} \mathrm{C}$ & $+1.8^{\circ} \mathrm{C}$ \\
& & & \\
\hline
\end{tabular}


Table 3. Correlation, $R$, for $b_{w}$ and independent variables $(E$ : elevation; $S$ : slope; $\alpha$ : aspect; $\mathrm{REA}_{r}$ : relative elevation attribute). Correlations significant at the 0.05 level are bold type; degrees of freedom are in parentheses

\begin{tabular}{lcrr}
\hline & $2004(103)$ & $2005(127)$ & $2006(142)$ \\
\hline$E$ & & $\mathbf{0 . 4 8 9}$ & $\mathbf{0 . 3 7 3}$ \\
$\alpha$ & 0.069 & -0.041 & -0.109 \\
$S$ & $\mathbf{0 . 3 6 3}$ & $\mathbf{0 . 3 2 3}$ & $\mathbf{0 . 2 4 3}$ \\
$\mathrm{REA}_{20}$ & $\mathbf{0 . 3 5 3}$ & $\mathbf{0 . 2 4 0}$ & 0.127 \\
$\mathrm{REA}_{40}$ & $\mathbf{0 . 4 8 2}$ & $\mathbf{0 . 3 6 4}$ & $\mathbf{0 . 3 1 6}$ \\
$\mathrm{REA}_{60}$ & $\mathbf{0 . 5 4 3}$ & $\mathbf{0 . 4 6 5}$ & $\mathbf{0 . 3 7 8}$ \\
$\mathrm{REA}_{80}$ & $\mathbf{0 . 5 5 3}$ & $\mathbf{0 . 4 9 7}$ & $\mathbf{0 . 4 0 8}$ \\
$\mathrm{REA}_{100}$ & $\mathbf{0 . 5 4 1}$ & $\mathbf{0 . 4 9 7}$ & $\mathbf{0 . 3 9 6}$ \\
$\mathrm{REA}_{120}$ & $\mathbf{0 . 5 2 5}$ & $\mathbf{0 . 4 8 3}$ & $\mathbf{0 . 3 7 9}$ \\
$\mathrm{REA}_{140}$ & $\mathbf{0 . 4 9 4}$ & $\mathbf{0 . 4 4 8}$ & $\mathbf{0 . 3 5 6}$ \\
$\mathrm{REA}_{160}$ & $\mathbf{0 . 4 5 6}$ & $\mathbf{0 . 4 0 6}$ & $\mathbf{0 . 3 3 1}$ \\
$\mathrm{REA}_{180}$ & $\mathbf{0 . 4 1 0}$ & $\mathbf{0 . 3 6 0}$ & $\mathbf{0 . 3 0 1}$ \\
$\mathrm{REA}_{200}$ & $\mathbf{0 . 3 6 1}$ & $\mathbf{0 . 3 1 3}$ & $\mathbf{0 . 2 6 9}$ \\
\hline
\end{tabular}

summer; in 2005 and 2006 it occurred between June and July, followed by a cool August with snowfalls that inhibited ablation and stopped it at the higher elevations.

The topographic attributes used as independent variables in this study were derived from a $10 \mathrm{~m}$ grid resolution digital terrain model (DTM) generated by processing high-resolution airborne laser altimetry (lidar) data, surveyed in September 2006. In order to assure a wider applicability of the extrapolation method, no meteorological variables were included.

\section{THE EXTRAPOLATION METHOD}

In the three observation years, residual snow patches were scarce and mostly retreated in remote areas at high altitude. Therefore, the net accumulation data that could be acquired were much fewer than the net ablation data, and not sufficient for the implementation of an extrapolation technique in the accumulation area.

Consequently, we decided to focus on $b_{\mathrm{w}}$ and $b_{\mathrm{s}}$ data rather than net balance, $b_{n}$. This approach also has the advantage of separately handling the accumulation and ablation processes, whereas the net quantities result from the combination of both.

The tested methods of extrapolation are single linear regressions and multiple regressions. The regression coefficients of the relationships obtained from the surveyed areas are used to calculate the mass balance on other, unsurveyed, areas.

\section{Winter balance extrapolation}

Both wind and avalanches relocate snow, forming a deposition pattern that is primarily governed by topography and is quite similar from year to year. This deposition pattern affects the runoff timing and magnitude during the melt season and the mass-balance distribution on glaciers (Luce and others, 1998; Hartman and others, 1999).

The independent variables selected to explain the winter balance spatial variability are reported in Table 3. In addition to the elevation, $E$, slope, $S$, and aspect, $\alpha$, we used a relative elevation attribute, $\mathrm{REA}_{n}$ calculated as follows:

$$
\mathrm{REA}_{r}=\overline{E_{r}}-E_{\mathrm{DTM}}
$$

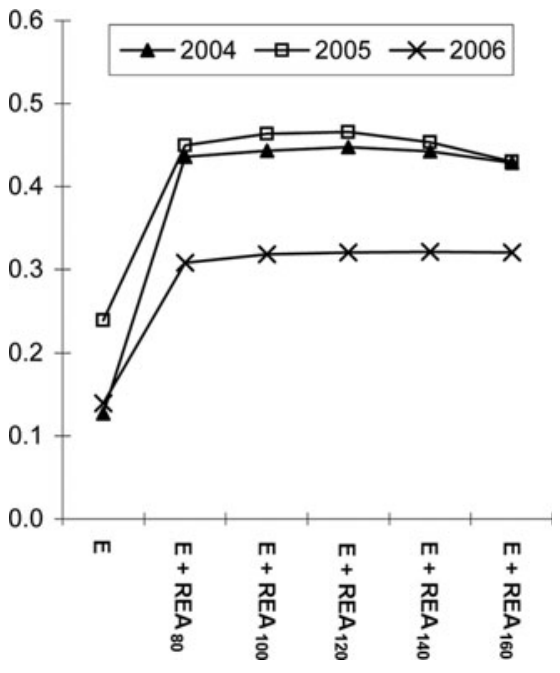

Fig. 3. Determination coefficient, $R^{2}$, of the linear regression between $b_{\mathrm{w}}$ and independent variables.

where $\bar{E}_{r}$ is the average elevation in a circular area with radius $r$ (in metres) around the gridcell with elevation $E_{\mathrm{DTM}}$. This topographic attribute expresses the degree of wind exposure of each gridcell. Its values are positive in hollows, depressions and at the foot of rock walls or steep slopes and negative on crests, peaks and generally convex areas. An interesting feature of this attribute lies in the possibility of adjusting the radius and ultimately the extent of the area that affects the local attitude to over- or under-accumulate snow.

As can be seen in Table $3, b_{\mathrm{w}}$ is directly correlated with $E$, $S$ and $\mathrm{REA}_{n}$ but not with $\alpha$. The direct correlation with $E$ is explicable by the positive precipitation gradient, even if above a certain altitude a reversal of the gradient is expected to exist; moreover, in most glaciers, $b_{w}$ is likely to decrease in the upper accumulation area because of snowdrift (Oerlemans and Hoogendoorn, 1989). In addition, the inclusion of $E$ among the independent variables allows us to account for possible ablation losses in the lower part of the glaciers. The direct correlation with $S$ does not have a similar physical basis and appears to be coincidental, since snow accumulation is expected to decrease with increasing $S$, due to avalanche action.

The $b_{\mathrm{w}}$ is directly correlated with $\mathrm{REA}_{r}$ and correlation increases up to a radius of $80-100 \mathrm{~m}$, then decreases. These results differ from a preliminary application of $\mathrm{REA}_{r}$ to a bare-ground area of the same catchment, located between 2600 and $2800 \mathrm{~m}$. In that case, the correlation between the snow w.e. and REA $r$ was higher (0.689), and optimized by a radius of $50 \mathrm{~m}$. This is probably due to greater terrain roughness, different snow metamorphism and lower wind speeds.

Two types of extrapolation schemes were implemented and compared. The first, W1, was a simple linear regression between $E$ and $b_{\mathrm{w}}$, while the second, W2, was a multiple linear regression among $b_{\mathrm{w},} E$ and $\mathrm{REA}_{r}$.

\section{Summer balance extrapolation}

In general, most of the energy used for melt on glaciers is supplied by radiation, followed by turbulent heat fluxes. Air temperature is a good predictor of melt since it is highly correlated with incoming longwave radiation and turbulent heat fluxes (Ohmura, 2001; Hock, 2005). In addition, it 

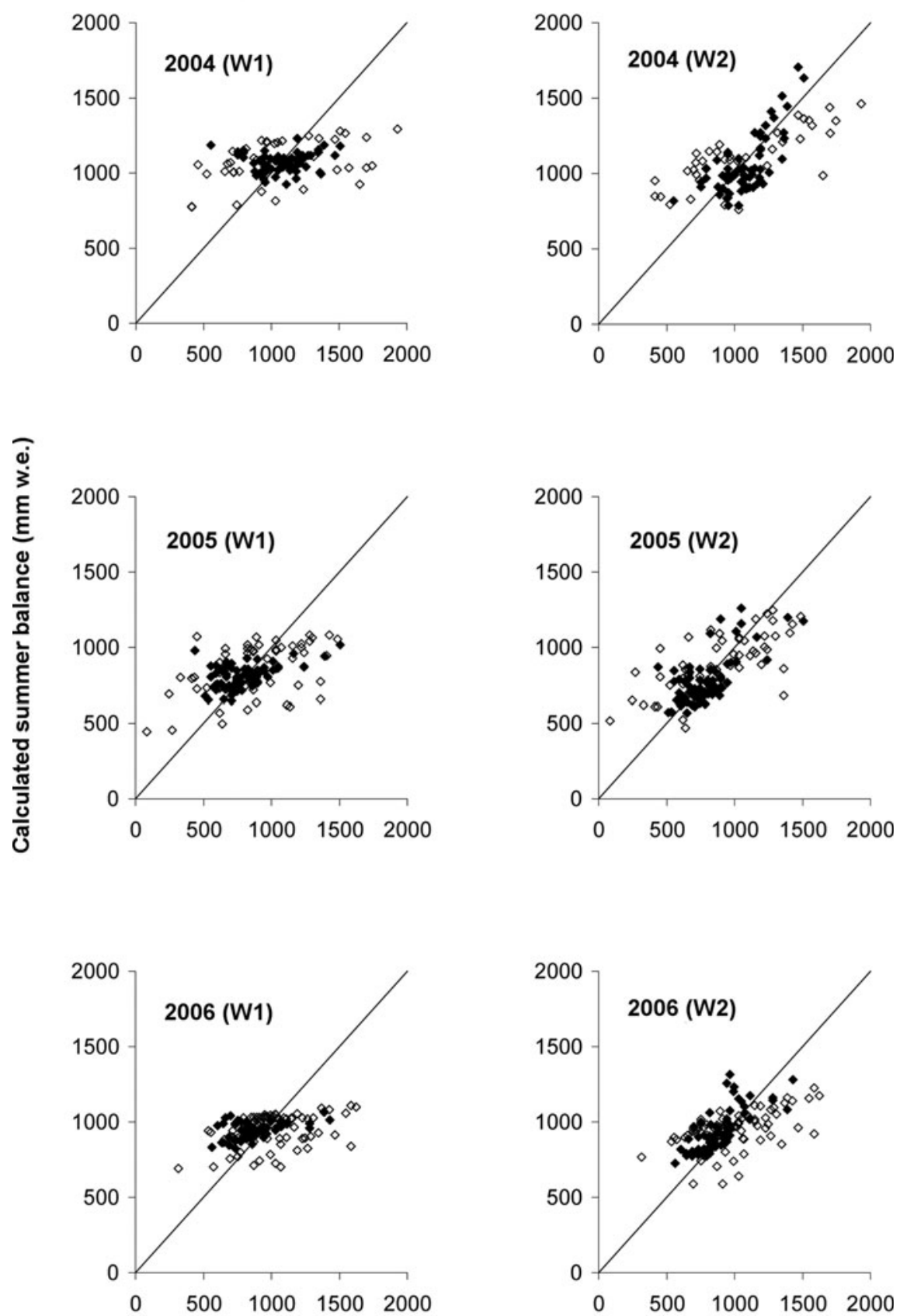

Measured summer balance ( $\mathrm{mm}$ w.e.)

Fig. 4. Measured versus calculated $b_{\mathrm{w}}$ using the $\mathrm{W} 1$ method $\left(b_{\mathrm{w}}\right.$ and $\left.E\right)$ and the $\mathrm{W} 2$ method $\left(b_{\mathrm{w}}, E\right.$ and REA $)$. Empty squares: La Mare; filled squares: Careser. The straight line indicates a 1:1 relationship.

controls the fraction of precipitation that falls as snow, which is crucial during the ablation season since it stops the ablation and increases the surface albedo. For this reason, the summer balance on glaciers is strongly altitudedependent.

However, our measurements at the AWS of La Mare glacier demonstrate that the net shortwave radiation dominates the energy flux during melt, confirming other observations with AWS operated on glaciers (Hock and Holmgren, 1996; Oerlemans, 2000; Greuell and Smeets, 2001; Strasser and others, 2004). Therefore, the use of measured or calculated shortwave radiation in addition to $E$ should optimize the capability to account for the high spatial variability of $b_{\mathrm{s}}$.
In confirmation of this, simple temperature-index ice- and snowmelt models have been appreciably improved by the inclusion of clear-sky direct or global radiation, yielding a more realistic temporal and spatial distribution of melt rates (Cazorzi and Dalla Fontana, 1996; Hock, 1999; Cazorzi and others, 2005; Pellicciotti and others, 2005).

Since the albedo differences among melting substrata (snow, firn and ice) strongly affect the melt rate, $b_{\mathrm{s}}$ data showed a spatial variability which was related to the relative amount of these substrata, and not just a function of topography. In order to spotlight the topographic effect on spatial data variability, they were preliminarily homogenized, using the average albedo differences among snow, firn and ice, as measured by the AWS and by a portable albedometer. 


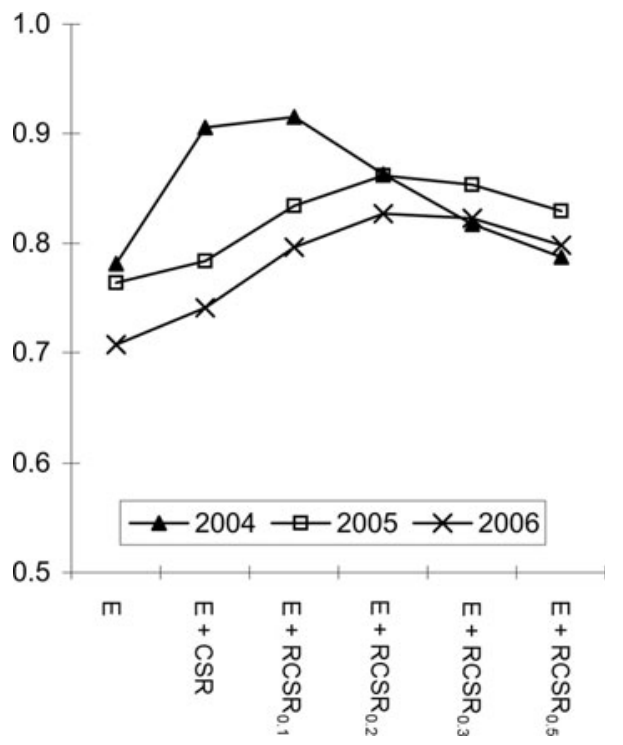

Fig. 5. Determination coefficient, $R^{2}$, of the linear regression between $b_{\mathrm{s}}$ and independent variables.

A preliminary application of the grid-distributed melt model developed by Cazorzi and others (2005) in the UVLA basin yielded encouraging results, but a spatial aggregation of simulation errors was clearly observed. The tuned model underestimated ablation on east-facing slopes and overestimated it on west-facing ones. The comparison of AWSmeasured shortwave global radiation versus computed clearsky radiation revealed a persistent diurnal cycle of cloud cover (mainly cumuliform clouds) during summer, with a minimum around sunrise and a maximum at sunset. This cycle is mainly triggered by the sun through thermal convection, which explains the timing of minima and maxima of cloud cover (Barry and Chorley, 1998).

Three different extrapolation schemes for $b_{\mathrm{s}}$ were implemented and compared. The first, S1, was a simple linear regression with $E$; the second, S2, was a linear multiple regression that included $E$ and daily-averaged clearsky radiation (CSR). The third, S3, was similar to the second, but used a normalized cloud-cover factor (NCCF) to reduce the CSR as a function of aspect.

Due to the observed diurnal cycle of cloud cover, the fraction of CSR available for melt is largest for the eastexposed sites and lowest for the west-exposed slopes. This phenomenon can be statistically simulated using a simple harmonic function that sets NCCF to 0 for the gridcells with aspect, $\alpha$, matching the sunrise azimuth and to 1 for the gridcells with aspect matching the sunset azimuth:

$$
\mathrm{NCCF}=0.5-0.5 \sin \left[\left(\alpha+\alpha_{0}\right) \xi+\alpha_{1}\right],
$$

in which $\alpha_{0}, \alpha_{1}$ and $\xi$ depend on daily sunrise and sunset azimuth. The reduced clear-sky radiation (RCSR) is then calculated as follows:

$$
\operatorname{RCSR}_{k}=\operatorname{CSR}(1-k N C C F),
$$

where $k$ is a calibration parameter ranging from 0 to 1 , which expresses the maximum reduction of CSR by cloud cover for the gridcells with $\alpha$ matching the sunset azimuth. It should be noted that the parameter $k$ does not require any additional meteorological data for its determination; in fact $k$ is selected by subsequent trials to fit the experimental $b_{\mathrm{s}}$ data as well as possible.

\section{Validation tests}

Three tests were conducted to assess the performance of the extrapolation methods. In particular, the aim was to highlight possible inadequacies in extrapolations, due to calibration data coming from poorly representative areas of the glaciated catchment. For the first test (T1 for winter balance, T4 for summer balance) half the data were randomly selected for calibration and the remaining data were used for validation. For the other two tests (T2 and T3 for winter balance, T5 and T6 for summer balance), we used the data measured on one glacier for calibration and the data from the other glacier for validation. For T2 and T5 the calibration data came from Careser glacier, while for T3 and T6 they came from La Mare glacier.

\section{RESULTS AND DISCUSSION}

The determination coefficients of the linear regressions between $b_{w}$ and independent variables are shown in Figure 3. The statistics denote a sharp and persistent improvement by including $\mathrm{REA}_{r}$ on the linear regression; $E$ alone accounts for less than half of the variance explained by multiple regression. The relationship of each regressor with the dependent variable is significant at the 0.05 level in $t$ tests. The optimal radius for the calculation of $\mathrm{REA}_{r}$ is $120 \mathrm{~m}$, although in 2006 the statistics indicate nearly identical results with 120, 140 and $160 \mathrm{~m}$. Better results, in terms of extrapolations, have to be expected for 2004 and 2005 , since in 2006 the correlation is noticeably lower.

The scatter plots in Figure 4 show comparisons between measured and calculated $b_{w}$, for the two extrapolation methods. The multiple regressions better match the observed data, the higher values in particular. A point-by-point comparison of measured vs calculated values revealed that the altitude alone underestimates $b_{\mathrm{w}}$ on snowdrifts and overestimates it for wind-scoured areas; whereas REA tends to overestimate $b_{\mathrm{w}}$ at lower altitudes and to underestimate it at higher altitudes. Combining the two attributes with a multiple linear regression considerably overcomes these drawbacks, even if two limitations are implied in the simplicity of this extrapolation method: the first is a scale dependency of snow redistribution, which varies with altitude and is not captured by a constant radius of $120 \mathrm{~m}$ in the calculation of REA $A_{r}$ the second is the inability to catch the drifts near to abrupt slope changes.

The high correlation between altitude and $b_{\mathrm{s}}$ ensures better estimates on unsampled areas compared to $b_{w}$. However, if $b_{\mathrm{s}}$ data come from an unrepresentative area of a glacier system, care should be taken in the extrapolation since systematic errors are possible.

Figure 5 shows the $R^{2}$ values for the three different extrapolation schemes of $b_{s}$. For S3 four $\mathrm{RCSR}_{k}$ were used, in order to optimize the value of the calibration parameter, $k$. The elevation alone explains a large proportion of the variability in $b_{\mathrm{s}}$. The effect of CSR on $b_{\mathrm{s}}$ is statistically significant in 2004 (t-test significance $<0.05$ ), while in 2005 and 2006 this improvement is not so clear (t-test significance $=0.128$ for 2005 and 0.054 for 2006). Better results for these two years are achievable by the simplified simulation of the diurnal cycle of cloud cover to reduce CSR. For 2005 and 2006 a $k$ value of 0.2 proves to be optimal and the trends of $R^{2}$ with the various combinations of independent variables are quite similar. The 2004 results show different behaviour, 

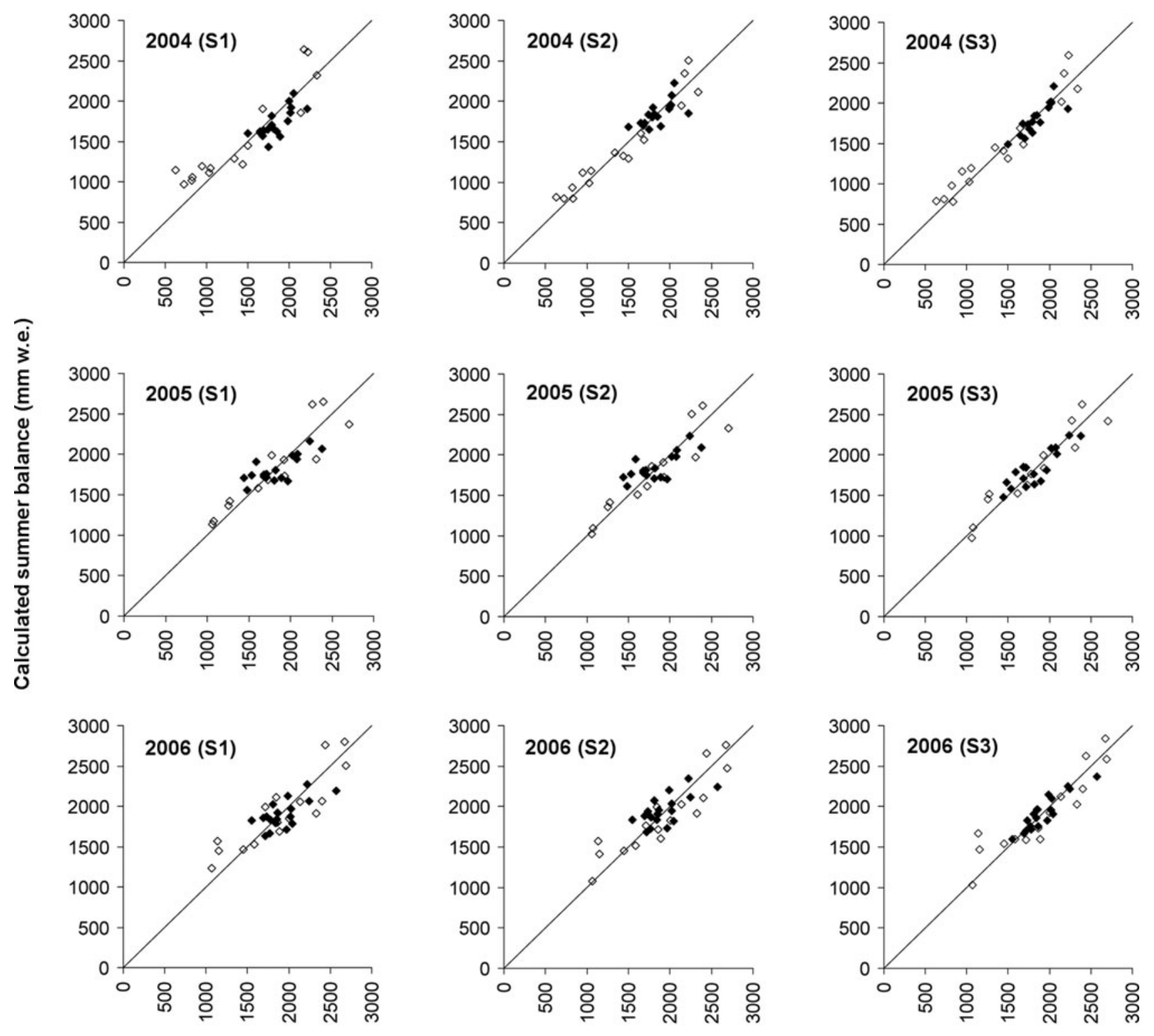

Measured summer balance ( $\mathrm{mm}$ w.e.)

Fig. 6. Measured versus calculated $b_{\mathrm{s}}$ with the $\mathrm{S} 1\left(b_{\mathrm{s}}\right.$ and $\left.E\right), \mathrm{S} 2\left(b_{\mathrm{s}}, E\right.$ and $\left.\mathrm{CSR}\right)$ and $\mathrm{S} 3\left(b_{\mathrm{s}}, E\right.$ and $\left.\mathrm{RCSR}{ }_{k}\right)$ methods. Empty squares: La Mare; filled squares: Careser. The straight line indicates a $1: 1$ relationship.

and the best correlation is achieved with a $k$ value of 0.1 . These differences are likely to be due to the climatic conditions of the three ablation seasons, as described above. The $t$ tests for calibrated $\mathrm{RCSR}_{k}$ provided a significance level always $<0.05$.

The scatter plots in Figure 6 compare the observed and calculated $b_{\mathrm{s}}$ using the three extrapolation methods. The plots of measured vs observed values show a closer alignment with the $1: 1$ line when $\mathrm{RCSR}_{k}$ is used. The scatter of points also diminishes, and with few exceptions the improvement from using CSR and $\mathrm{RCSR}_{k}$ is evident. As observed in the regression analysis, the inclusion of the cloud-cover daily cycle yields better results in 2005 and 2006 than in 2004.

The results of the validation tests are shown in Tables 4 and 5, where the accuracy of each extrapolation method is expressed in terms of $R^{2}$ and root-mean-square error (rmse). For winter balance (Table 4), the tests confirm the findings of the regression analysis, since the multiple regressions yield higher $R^{2}$, lower rmse and $b_{\mathrm{w}}$ that ranges closer to the observed values, in almost all cases. For summer balance (Table 5), the method which combines $E$ and $\mathrm{RCSR}_{k}$ provides consistently better results. In fact, the CSR-based extrapolation is sometimes worse than the simple linear regression of summer balance vs altitude. Specifically, this happens when Careser data are used to infer La Mare data, or vice versa, leading to systematic under- or overestimations of $b_{\mathrm{s}}$. The different prevalent aspect of the two glaciers makes them differently affected by the cloud-cover daily cycle. The reduction of CSR by clouds is more effective on Careser glacier due to a wider presence of southern and western slopes.

The best-performing regression methods were combined to extrapolate the field data and calculate the net annual mass balance, $b_{n}$, on the surface of the entire UVLA glacier system. A multiple regression of $E$ and $\mathrm{REA}_{120}$ was used to extrapolate $b_{\mathrm{w}}$. For $b_{\mathrm{s}}$ a multiple regression of $E$ and $\mathrm{RCSR}_{k}$ was employed, with $k$ ranging from 0.1 (for 2004) to 0.2 (for 
Table 4. Accuracy of the two $b_{\mathrm{w}}$ extrapolation methods, $\mathrm{W} 1$ ( $b_{\mathrm{w}}$ and $E)$ and $\mathrm{W} 2\left(b_{\mathrm{w}}, E\right.$ and $\left.\mathrm{REA}_{r}\right)$. Bold type indicates a determination coefficient, $R^{2}$, significant at the 0.05 level and $n$ is the sample size

\begin{tabular}{|c|c|c|c|c|c|}
\hline Test & & $R^{2}$ & rmse & Range & Mean \\
\hline \multirow[t]{3}{*}{ T1 2004} & Measured $(n=52)$ & & & $458-1933$ & 1045 \\
\hline & Calculated W1 & 0.073 & 313 & 794-1361 & 1101 \\
\hline & Calculated W2 & 0.372 & 252 & $713-1538$ & 1053 \\
\hline \multirow{3}{*}{ T2 2004} & Measured $(n=38)$ & & & 413-1933 & 1066 \\
\hline & Calculated W1 & 0.194 & 391 & 984-1142 & 1076 \\
\hline & Calculated W2 & 0.248 & 368 & 904-1332 & 1114 \\
\hline \multirow[t]{3}{*}{ T3 2004} & Measured $(n=66)$ & & & 552-1509 & 1075 \\
\hline & Calculated W1 & 0.012 & 190 & 883-1259 & 1061 \\
\hline & Calculated W2 & 0.510 & 283 & $476-2203$ & 967 \\
\hline \multirow[t]{3}{*}{ T1 2005} & Measured $(n=64)$ & & & $248-1507$ & 875 \\
\hline & Calculated W1 & 0.260 & 245 & 566-1012 & 801 \\
\hline & Calculated W2 & 0.562 & 190 & $508-1177$ & 815 \\
\hline \multirow[t]{3}{*}{ T2 2005} & Measured $(n=56)$ & & & 83-1487 & 881 \\
\hline & Calculated W1 & 0.225 & 298 & $356-1112$ & 843 \\
\hline & Calculated W2 & 0.483 & 253 & $556-1163$ & 890 \\
\hline \multirow[t]{3}{*}{ T3 2005} & Measured $(n=72)$ & & & 439-1507 & 792 \\
\hline & Calculated W1 & 0.235 & 172 & $692-1029$ & 842 \\
\hline & Calculated W2 & 0.461 & 173 & $466-1379$ & 723 \\
\hline \multirow[t]{3}{*}{ T1 2006} & Measured $(n=71)$ & & & 555-1585 & 943 \\
\hline & Calculated W1 & 0.092 & 203 & $637-1169$ & 963 \\
\hline & Calculated W2 & 0.230 & 189 & 509-1334 & 946 \\
\hline \multirow[t]{3}{*}{ T2 2006} & Measured $(n=80)$ & & & $317-1625$ & 996 \\
\hline & Calculated W1 & 0.133 & 270 & 502-1137 & 892 \\
\hline & Calculated W2 & 0.258 & 244 & $567-1145$ & 897 \\
\hline \multirow[t]{3}{*}{ T3 2006} & Measured $(n=63)$ & & & $563-1431$ & 886 \\
\hline & Calculated W1 & 0.203 & 189 & 886-1098 & 993 \\
\hline & Calculated W2 & 0.532 & 159 & $737-1448$ & 981 \\
\hline
\end{tabular}

2005 and 2006). The difference between $b_{\mathrm{w}}$ and $b_{\mathrm{s}}\left(b_{\mathrm{n}}\right)$ calculated for the entire glacier system was $-450,-1064$ and -1011 mm w.e. in 2004, 2005 and 2006, respectively.

The reliability of the extrapolation method was assessed against $b_{\mathrm{n}}$ measured at the ablation stakes and the snowcover maps surveyed during the summer. This was done with the assumption that the isolines of annual mass balance run roughly parallel to the transient snowline (Kamniansky and Pertziger, 1996).

In Figure 7, the 2004 snow-cover distribution on four dates is reported, alongside the calculated $b_{n}$. As can be seen, the multiple-regression method better matches the lower boundary of the snow cover at the end of the ablation season, in particular on north-facing slopes. Above the equilibrium line, however, the calculated residual snow cover is more continuous than in reality. Furthermore, $b_{\mathrm{n}}$ appears to be overestimated at the highest altitudes and on north-facing steep slopes. In the ablation area, the distribution of $b_{\mathrm{n}}$ calculated by linear regression with $E$ appears to be excessively simplified with respect to the observed snowcover pattern. The use of multiple regression yields more realistic results, and some specific features are better represented. Among these is the reduction (increase) of ablation on north-facing (south-facing) slopes and in highaccumulation (low-accumulation) areas.

The scatter plots in Figure 8 show the observed and calculated $b_{\mathrm{n}}$ at the ablation stakes in 2004. With few exceptions, the results of the multiple-regression method are in closer agreement with measurements. The improvement is greater on Careser glacier. On La Mare glacier, good results are obtained both in the ablation and accumulation areas,
Table 5. Accuracy of the three $b_{\mathrm{s}}$ extrapolation methods $\mathrm{S} 1\left(b_{\mathrm{s}}\right.$ and $E), \mathrm{S} 2\left(b_{\mathrm{s}}, E\right.$ and $\left.\mathrm{CSR}\right)$ and S3 $\left(b_{\mathrm{s}}, E\right.$ and $\left.\mathrm{RCSR}_{k}\right)$. Determination coefficients, $R^{2}$, are significant at the 0.05 level and $n$ is the sample size

\begin{tabular}{|c|c|c|c|c|c|}
\hline & & $R^{2}$ & rmse & Range & Mean \\
\hline \multirow[t]{4}{*}{ T4 2004} & \multicolumn{3}{|c|}{ Measured $(n=16)$} & $831-2339$ & 1738 \\
\hline & Calculated S1 & 0.798 & 358 & 908-3109 & 1892 \\
\hline & Calculated S2 & 0.889 & 247 & $738-2833$ & 1855 \\
\hline & Calculated S3 & 0.901 & 275 & 698-2972 & 1884 \\
\hline \multirow[t]{4}{*}{ T5 2004} & \multicolumn{3}{|c|}{ Measured $(n=16)$} & 628-2339 & 1407 \\
\hline & Calculated S1 & 0.848 & 386 & $1286-2529$ & 1706 \\
\hline & Calculated S2 & 0.850 & 383 & $1281-2527$ & 1703 \\
\hline & Calculated S3 & 0.923 & 236 & $1024-2527$ & 1568 \\
\hline \multirow[t]{4}{*}{ T6 2004} & \multicolumn{3}{|c|}{ Measured $(n=17)$} & $1499-2220$ & 1850 \\
\hline & Calculated S1 & 0.540 & 288 & 1308-1939 & 1589 \\
\hline & Calculated S2 & 0.411 & 141 & $1696-2262$ & 1873 \\
\hline & Calculated S3 & 0.743 & 143 & $1445-2128$ & 1741 \\
\hline \multirow[t]{4}{*}{ T4 2005} & \multicolumn{3}{|c|}{ Measured $(n=15)$} & $1061-2706$ & 1928 \\
\hline & Calculated S1 & 0.771 & 261 & 951-2959 & 2003 \\
\hline & Calculated S2 & 0.782 & 243 & 848-2872 & 1992 \\
\hline & Calculated S3 & 0.845 & 215 & $813-2872$ & 1959 \\
\hline \multirow{4}{*}{ T5 2005} & \multicolumn{3}{|c|}{ Measured $(n=13)$} & $1061-2706$ & 1792 \\
\hline & Calculated S1 & 0.833 & 248 & 989-2863 & 1827 \\
\hline & Calculated S2 & 0.806 & 282 & 1096-2925 & 1890 \\
\hline & Calculated S3 & 0.892 & 173 & $937-2702$ & 1801 \\
\hline \multirow[t]{4}{*}{ T6 2005} & \multicolumn{3}{|c|}{ Measured $(n=17)$} & $1439-2378$ & 1830 \\
\hline & Calculated S1 & 0.590 & 175 & $1541-2132$ & 1795 \\
\hline & Calculated S2 & 0.509 & 262 & $1811-2432$ & 2018 \\
\hline & Calculated S3 & 0.752 & 129 & $1450-2250$ & 1827 \\
\hline \multirow[t]{4}{*}{ T4 2006} & \multicolumn{3}{|c|}{ Measured $(n=17)$} & $1065-2572$ & 1853 \\
\hline & Calculated S1 & 0.732 & 189 & 1253-2159 & 1818 \\
\hline & Calculated S2 & 0.659 & 200 & $983-2270$ & 1853 \\
\hline & Calculated S3 & 0.876 & 129 & $1013-2333$ & 1804 \\
\hline \multirow[t]{4}{*}{ T5 2006} & \multicolumn{3}{|c|}{ Measured $(n=16)$} & 1065-2688 & 1897 \\
\hline & Calculated S1 & 0.772 & 252 & 1300-2767 & 1947 \\
\hline & Calculated S2 & 0.785 & 243 & $1264-2740$ & 1925 \\
\hline & Calculated S3 & 0.814 & 222 & 1055-2794 & 1910 \\
\hline \multirow[t]{4}{*}{ T6 2006} & \multicolumn{3}{|c|}{ Measured $(n=18)$} & $1457-2572$ & 1927 \\
\hline & Calculated S1 & 0.463 & 181 & $1597-2247$ & 1874 \\
\hline & Calculated S2 & 0.454 & 223 & 1800-2485 & 2062 \\
\hline & Calculated S3 & 0.814 & 105 & $1615-2329$ & 1901 \\
\hline
\end{tabular}

even if differences up to $1200 \mathrm{~mm}$ persist at single points. Similar results are obtained for 2005 and 2006. A steady overestimation of net ablation can be seen in proximity to the observed ELA, which is probably related to the strong mass-balance gradient in that area.

The discrepancies observed in the final $b_{\mathrm{n}}$ output (local overestimation of accumulation areas and of mass balance) are primarily due to incorrect $b_{\mathrm{w}}$ estimates in areas of avalanche redistribution, at high altitude and near abrupt slope changes. The strong mass-balance gradient observed in proximity to the ELA is probably due to fresh summer snow, which tends to persist longer on snow-covered than on bare-ice areas. To capture the complexity of these processes is beyond the aims of this work.

\section{CONCLUDING REMARKS}

Topographic attributes easily derived from a DTM $(E, \alpha$, CSR, NCCF, REA $r$ ) allow for a satisfactory interpretation of the dominant processes governing the mass exchange on glaciers. A regression analysis of accumulation and ablation data surveyed during three years was conducted separately 


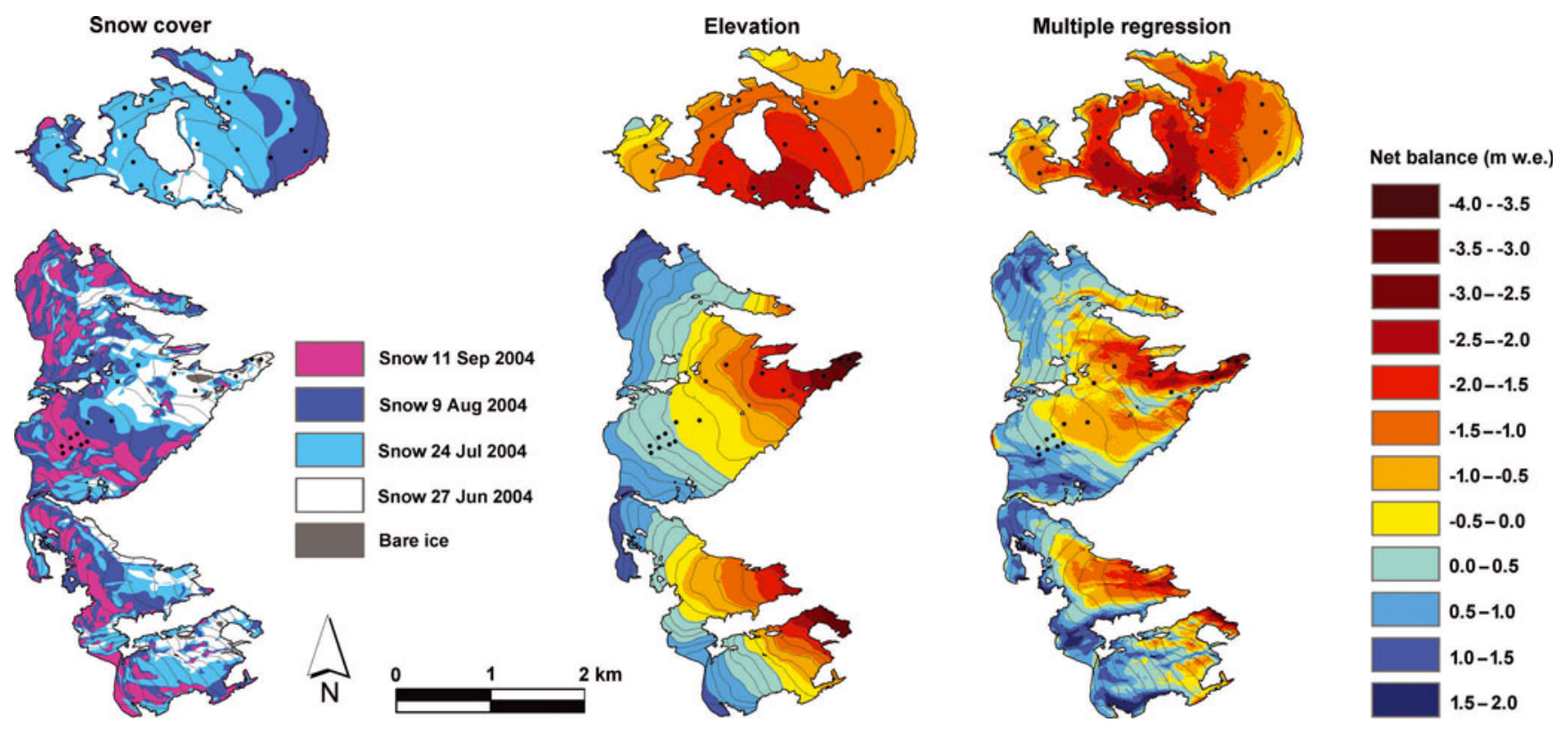

Fig. 7. Snow-cover maps for four dates in 2004 (left) and net-balance maps for the same year, obtained by single linear regression of altitude (centre) and by multiple regression (right). The black dots are the ablation stakes. Careser glacier has been translated to fit in the figure.

for $b_{\mathrm{w}}$ and $b_{\mathrm{s}}$ and was more problematic for the former. The amount of explainable variability in the observed data was nearly double for $b_{\mathrm{s}}$ with respect to $b_{\mathrm{w}}$. Moreover, whereas use of the altitude alone allows for reasonable extrapolation of ablation data, the same cannot be said for accumulation.

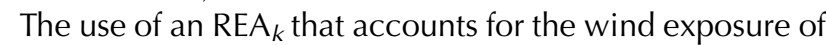
a site improves the ability to explain the spatial variability of the accumulation processes. Indeed, snow redistribution on glaciers is mainly controlled by wind action. The use of clearsky radiation in the summer balance regression equation is greatly improved by the introduction of a simple function that relates aspect to cloud cover (NCCF), allowing for a correction of CSR according to the daily cycle of cloud cover.

The final regression equations were tested and used to extrapolate the net balance to the entire glacier system of the basin. Some aspects remain unsolved. Among these is the snow redistribution by avalanches, the formation of snowdrifts in the proximity of abrupt slope changes or on the lee side of obstacles, and the decrease of winter balance above a certain altitude due to increased effectiveness of wind erosion.

An ultimate approach probably requires a fully distributed energy- and mass-balance model, but it is worth noting that in the method proposed here no other information besides topography is required.

\section{ACKNOWLEDGEMENTS}

The authors thank the Comitato Glaciologico Trentino - SAT, ENel SpA, Provincia Autonoma di Trento, Museo Tridentino di Scienze Naturali and Università di Trento for support during the fieldwork and for providing the meteorological and lidar data. Special thanks to R. Seppi, to the friends of CGT and to the students who have contributed to the data surveys. This work was supported by the Italian MURST grant PRIN 2005 (30\%) and UNIPD 2007 project 'Climate change effects on the cryosphere and hydrology of alpine watersheds'.
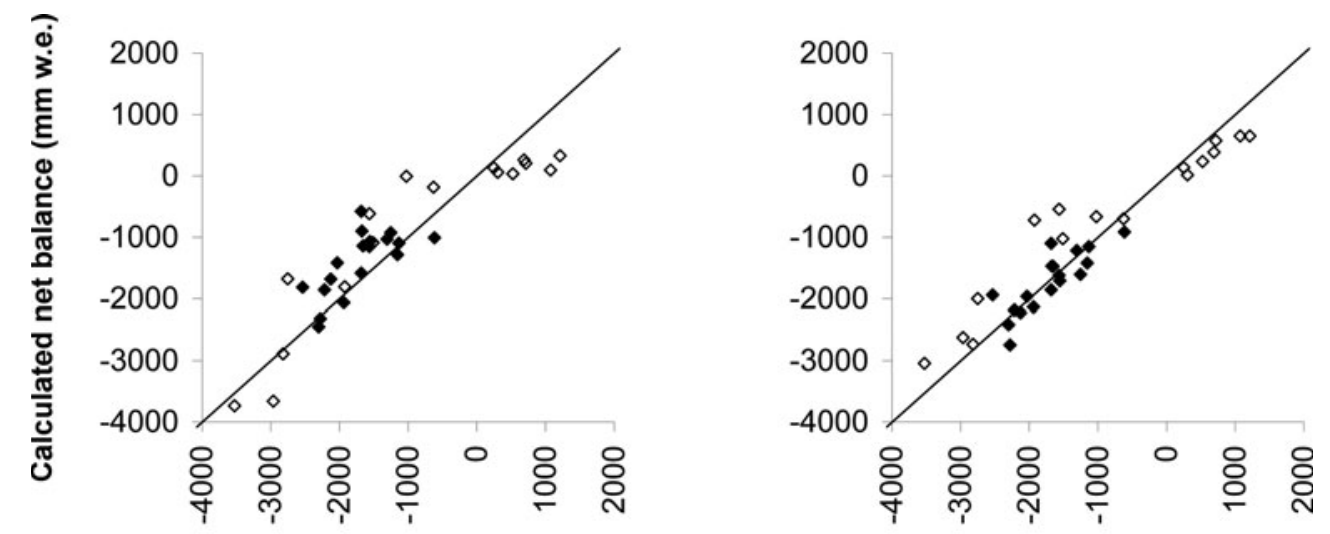

Measured net balance ( $\mathrm{mm}$ w.e.)

Fig. 8. Measured versus calculated $b_{\mathrm{n}}$ at the ablation stakes of Careser glacier (filled squares) and La Mare glacier (empty squares) in 2004, on the left by simple linear regression with $E$, on the right by multiple regression. 


\section{REFERENCES}

Barry, R.G. and R.J. Chorley. 1998. Atmosphere, weather and climate. Seventh edition. London and New York, Routledge.

Benn, D.I. and D.J.A. Evans. 1998. Glaciers and glaciation. London, Arnold.

Carturan, L. and R. Seppi. 2007. Recent mass balance results and morphological evolution of Careser Glacier (Central Alps). Geogr. Fís. Din. Quat., 30(1), 33-42.

Cazorzi, F. and G. Dalla Fontana. 1996. Snowmelt modelling by combining air temperature and a distributed radiation index. J. Hydrol., 181(1-4), 169-187.

Cazorzi, F., L. Carturan and G. Dalla Fontana. 2005. Simulazione della fusione in ambiente glaciale con un modello distribuito ad indice morfoenergetico. I'Acqua, 3, 23-32.

Fountain, A.G., P. Jansson, G. Kaser and M. Dyurgerov. 1999. Summary of the Workshop on methods of mass balance measurements and modelling, Tarfala, Sweden August 10-12, 1998. Geogr. Ann., 81A(4), 461-465.

Fountain, A.G. and A. Vecchia. 1999. How many stakes are required to measure the mass balance of a glacier? Geogr. Ann., 81A(4), 563-573.

Furbish, D.J. and J.T. Andrews. 1984. The use of hypsometry to indicate long-term stability and response of valley glaciers to changes in mass transfer. J. Glaciol., 30(105), 199-211.

Greuell, W. and P. Smeets. 2001. Variations with elevation in the surface energy balance on the Pasterze (Austria). J. Geophys. Res., 106(D23), 31,717-31,727.

Hartman, M.D. and 6 others. 1999. Simulations of snow distribution and hydrology in a mountain basin. Water Resour. Res., 35(5), 1587-1603.

Hock, R. 1999. A distributed temperature-index ice- and snowmelt model including potential direct solar radiation. J. Glaciol., 45(149), 101-111.

Hock, R. 2005. Glacier melt: a review on processes and their modelling. Progr. Phys. Geogr., 29(3), 362-391.

Hock, R. and B. Holmgren. 1996. Some aspects of energy balance and ablation of Storglaciären, northern Sweden. Geogr. Ann., 78A(2-3), 121-131.

Holmlund, P. and P. Jansson. 1999. The Tarfala mass balance programme. Geogr. Ann., 81A(4), 621-631.
Kamniansky, G.M. and F.I. Pertziger. 1996. Optimization of mountain glacier mass balance measurements. Z. Gletscherkd. Glazialgeol., 32, 167-175.

Kaser, G., A. Fountain and P. Jansson. 2003. A manual for monitoring the mass balance of mountain glaciers. Paris, UNESCO. (IHP-VI Technical Documents in Hydrology 59.)

Krimmel, R.M. 1999. Analysis of difference between direct and geodetic mass balance measurements at South Cascade Glacier, Washington. Geogr. Ann., 81A(4), 653-658.

Luce, C.H., D.G. Tarboton and K.R. Cooley. 1998. The influence of the spatial distribution of snow on basin-averaged snowmelt. Hydrol. Process., 12(10-11), 1671-1683.

Oerlemans, J. 2000. Analysis of a 3 year meteorological record from the ablation zone of Morteratschgletscher, Switzerland: energy and mass balance. J. Glaciol., 46(155), 571-579.

Oerlemans, J. and N.C. Hoogendoorn. 1989. Mass-balance gradients and climatic change. J. Glaciol., 35(121), 399-405.

Ohmura, A. 2001. Physical basis for the temperature-based meltindex method. J. Appl. Meteorol., 40(4), 753-761.

Østrem, G. and M. Brugman. 1991. Glacier mass-balance measurements. A manual for field and office work. Saskatoon, Sask., Environment Canada. National Hydrology Research Institute. (NHRI Science Report 4.)

Pellicciotti, F., B.W. Brock, U. Strasser, P. Burlando, M. Funk and J.G. Corripio. 2005. An enhanced temperature-index glacier melt model including shortwave radiation balance: development and testing for Haut Glacier d'Arolla, Switzerland. J. Glaciol., 51(175), 573-587.

Pelto, M.S. and C. Hedlund. 2001. Terminus behavior and response time of North Cascade glaciers, Washington, USA. J. Glaciol., 47(158), 497-506

Schwarb, M. 2000. The Alpine precipitation climate: evaluation of a high-resolution analysis scheme using comprehensive raingauge data. (MSc thesis, ETH Zürich.)

Strasser, U., J. Corripio, F. Pellicciotti, P. Burlando, B. Brock and M. Funk. 2004. Spatial and temporal variability of meteorological variables at Haut Glacier d'Arolla (Switzerland) during the ablation season 2001: measurements and simulations. J. Geophys. Res., 109(D3), D03103. (10.1029/2003JD003973.)

Zanon, G. 1982. Recent glaciological research in the OrtlesCevedale region (Italian Alps). Geogr. Fís. Din. Quat., 5(1), 75-81. 